\title{
VIRTUAL REALITY TO SUPPORT TECHNICAL KNOWLEDGE IN CULTURAL HERITAGE. THE CASE STUDY OF CRYPTOPORTICUS IN THE ARCHAEOLOGICAL SITE OF EGNATIA (ITALY)
}

\author{
E. Cantatore ${ }^{1, *}$, M. Lasorella $^{1}$, F. Fatiguso ${ }^{1}$ \\ ${ }^{1}$ Polytechnic of Bari, 70126 Bari BA, Italy - (elena.cantatore, margherita.lasorella, fabio.fatiguso)@poliba.it
}

Commission II - WG II/8

KEY WORDS: Virtual Tour, Technical knowledge, Cultural heritage, Archaeological site of Egnatia

\begin{abstract}
:
Digitalization and interactivity of reality in Augmented and Virtual Environments represent the synergic union between current technology potentialities and smartness of users in going beyond the traditional perception of real environment. As it is well-known, touristic bodies already taken advantages of Virtual Environments as cultural and touristic promotion of historic and archaeological sites. However, the analysis of potentialities in supporting technical community and professionals are still underway. Starting from the survey of instruments and protocols in previous experiences, the work presents a methodological flow aimed to create a virtual environment using $360^{\circ}$ images - Virtual Tour - where the first phase of technical knowledge in historic sites can be resumed. In detail, a double level of knowledge can be reached: firstly, a virtual environment containing information about the actual state of conservation, then an upgraded one with historic and technical information (e.g. reports, images, surveys, etc.) added in an interactive as well intuitive way. The protocol has been applied to the undergrounded Cryptoporticus of Egnatia, an archaeological site in Apulia Region (Italy).
\end{abstract}

\section{INTRODUCTION}

During the last thirty years, the progress of digital technologies allowed the development of tools and methods for the acquisition of geometric information of artefacts featured by any size and a high degree of accuracy and resolution, as well as for their re-proposition as virtual types of reality (Russo, Manferdini, 2015).

Among the others, diagnostic and survey sectors involved historical and architectural heritage underwent a real revolution in the last decade. This was possible due to the creation of specific tools involved in the environmental data acquisition (the laser scanner, the digital photogrammetry and panoramic photos), as well in managing the acquired data as multidimensional digital environments in which various types of information (metric, geometric, diagnostic and documentary) can be associated (De Fino et al., 2019a, 2019b).

This work provides an innovative methodology useful in collecting, representing and managing data related to the state of maintenance of historical and cultural heritage through Virtual Reality tools.

Virtual Reality (VR) or Virtual Environment, by definition, allows an immersive experience within a digitalized environment (quite similar to the real one) that could not be necessarily close to the users. In fact, VR allows the visualization - in high-resolution and three-dimensional mode and the interaction - in a real-time - with virtual environments and objects, providing a full fruition to users (De Paolis, 2012; Milgram, Kishino, 1994). Furthermore, Virtual Reality can be identified as an advanced IT tool or a container of multidisciplinary information. The interaction between user and environment is guaranteed by the use of traditional interfaces (monitors, keyboards and mouse) or by sophisticated devices (helmets, visors and motion sensors); those ones are the result of technological innovation process in transforming perception and participation in the created environment, moving from a virtual to the immersive level. Due to these features, VR represents a system of multidisciplinary tools applied in several fields as the medicine (Fuchs et al., 1998; Pietrzak et al., 2006) the aeronautics (Julier et al., 1999), the pedagogical and educational sectors; for them, VR tools aimed at disseminate and text knowledge contents in an innovative and interactive way (Ben-Joseph et al., 2001; Cobb et al., 2002; Gillet et al., 2004; Kaufmann, Schmalstieg, 2002). Moreover, VR reaches the widest application in entertainment field, from the gaming (De Souza e Silva, Delacruz, 2006; Rashid et al., 2006) to the free time activities (Romero et al., 2004; Roussou, 2004).

The visualization and/or the reproduction of environments, as well as the explanation of artefacts (describing tangible and intangible values) represent the core activities of history, architecture and archaeology. Here, the virtual reality supports these fields in an obvious way (De Paolis, 2012). In fact, the creation of a virtual-historic environment become functional to represent the historical and scientific values, as well as to evaluate the historical-temporal transformations of the environments themselves, focusing on previous activities and future evaluation for processes currently underway. Therefore, in the field of Cultural Heritage, Virtual Reality finds its implementation in two main areas:

- the first one aims at using, communicating, disseminating and enhancing cultural heritage, also borrowing applications, such as the WebGis-3D platforms, to share knowledge; the use of these platforms allows to pass the

\footnotetext{
* Corresponding author
} 
geographic boundaries and ensures a first level of knowledge for cultural sites, overlooking the physical presence on site of users (Cardaci, Versaci, 2013). In that case, digital models constitute the basic accessible data within the platforms allowing to a wider public the remote fruition of cultural heritage usually inaccessible or unknown (Gabellone, 2014). The created virtual environments are conceived as a platform where representations (maps, satellite images, 3D models and links to documents) and associated information are structured at different scales, creating spaces for sharing knowledge as well multidisciplinary and interoperability dataset (Meschini, 2011). Here, two projects are part of that application field:

a) ARCHEOGUIDE (Vlahakis et al., 2001) (Augmented Reality-based Cultural Heritage On-site GUIDE), funded by the European community, had the aim to provide a personal assistant to tourists in specific cultural sites; the resulting system used the AR technology to rebuild ancient ruins and to render environments in real time taking into account both position and orientation of tourist within the site;

b) iTACITUS (Zoellner et al., 2007), European project in the objectives of the "Mobile Augmented Reality (AR) Guide Framework for Cultural Heritage (CH)", was proposed as a mobile information system of cultural heritage. It aimed to collect and to make available to tourists the digital content - carefully organized and referenced to the real environment - related to historical and architectural information of the site in a 3D digital environment.

Here, Virtual Reality technologies allowed the enhancement of historic environments, describing their evolution and showing their features. So, the navigation within the virtual environment allows the visualization of details positioned in poorly accessible areas, obtaining detailed information compared to the traditional way to enjoy them. Virtual Reality systems are also able to guide users in the un-real spaces allowing their exploring through specific paths, answering to different interests of various users.

- the second relevant field is related to the data management and cataloguing by the creation of databases: thus, heritage and any kind of related data (historical documentation, historical photographs, and metric measurements) are categorized in the most appropriate way. This operative approach was borrowed from business applications and it is essential in supporting the protection and conservation of Cultural Heritage. Following that purpose, the INSITER project (Roders et al., 2016) (Intuitive Self-Inspection Techniques using Augmented Reality for construction, refurbishment and maintenance of energy-efficient buildings made of prefabricated components) experimented AR and VR techniques for data management and processes of heritage over the time, even if closely related to the management of energy efficiency processes.

Focusing on its program designing, the Virtual Reality consists in two main components: the virtual environment, where the end user will be introduced using the application, and the interface, a set of elements with which users will interact to move in the environment and to control the experience. Focus on the creation process, virtual environment essentially consists in three elements: 1.the Content, defined as the system of information within the environment;

2.the Geometry of created virtual space strictly related to the size and/or proportions of environment;

3.the Dynamics as the relations in force between contents in virtual environment.

Different data types and formats in virtual environment constitute the content, such as three-dimensional models (CAD, point clouds or polygonal mesh), media files (images, video and audio) or text files (archive documents, reports). Analysing the nature of these data in the Cultural Heritage sector, Virtual environments contain specialist data, useful to several and pertinent sub-fields such as:

- diagnostics information in defining the state of conservation and decay of Cultural Heritage (Paolini et al., 2005) after specific tests;

- restoration data, in which the simulation of activities in virtual environments allows the experimentation of choices in aesthetic and scientific points of view (Limoncelli, 2011);

- tourism, for the use and the promotion of buildings - or parts - in part or totally loosed in an immersive, interactive and real-time way (Bruno et al., 2010; Guttentag, 2010).

In that framework, the IT@CHA project - "Italian technologies for advanced applications in Cultural Heritage," PON Research and Competitiveness 2007-2013 - is the most representative case. Here, the CETMA consortium, project leader, developed innovative and technological solutions useful in supporting technicians, operators and bodies involved in the enhancement process for archaeological sites, museums, monumental and cultural sites. Activities aimed at the implementation of advanced three-dimensional models, through which users were able to visit and to explore historical contexts in an immersive, interactive and real-time mode.

Focus on the geometry, the virtual environment is created using three-dimensional CAD models or point clouds and polygonal meshes derived from the laser scanning or digital photogrammetry techniques. The recent scientific literature demonstrates a good quality in 3D reconstructions derived from photogrammetry, moving scientists in preferring that technique above all for the creation of virtual realities, as well for the dissemination, cataloguing and enhancement of cultural heritage. Furthermore, the restrained costs of equipment (cameras), the ease data acquisition and processing (image or video files) and the high reliability of produced outputs (thanks to the improvement of Structure-From-Motion algorithms) allow archaeologists, experts in cultural heritage, architects, engineers, scholars and researchers to have powerful info-graphic tools that increasingly support, or even replace, three-dimensional models obtained with the rangebased techniques (D'Auria, 2018).

Finally, the relations in virtual environment can be classified into three macro-categories:

- the hotspots are sensitive areas that allow the interactions in virtual environment such as the navigation, the activation of pop-up windows containing inner data and the connection to external contents (e.g. web) (Aznoora et al., 2009);

- the orientation maps display the plans of the virtualized environment; the morpho-distributive information are associated with the environment itself. Moreover, orientation maps are useful to correlate and to connect 
different virtual rooms by radars (specific hotspots). In detail, the use of orientation maps allows to significantly improve the user experience above all for architectures featured by high extension or developed on several levels;

- the Menu is the list of environments that constitute the virtual model.

However, the data management of Cultural Heritage during the phase of knowledge is still excluded by VR application. In fact, focusing on the Cultural Heritage Regulations, the processes of knowledge and diagnosis, as well the interactions between bodies and technical operators involved in their protection activities, the assessment of the state of the sites and conservation pass through three specific activities by technical operator (or, as very often happens, technicians):

- a preliminary geometric and photographic survey on-site usually followed by other ones due to the complexity and/or the accessibility of the site - (Docci, Maestri, 1994);

- analysis of the state of decay on-site; here, the expert operator, using simple devices, notes down on the socalled "survey sheets" all the appreciable information (extent and width of the main cracks and pathologies). In addition, the operator carries out a photographic survey of decays useful during the succeeding phases (Frate, 2010);

- elaboration of architectural and thematic maps, as graphic representations of the state of decay. The preparation of these maps consists of manual operations by expert operators, based on previous inspections, photographic acquisitions and - above all - their knowledge and skills. These documents have a fundamental role in defining consequent interventions and so in supporting technician choices with managing and preservation authorities (Carbonara, 2012; Marino, 1990).

Therefore, the careful reading of the state of conservation of artefacts and the on-site investigation become the key elements of the described process. However, annotation and investigation techniques still follow very traditional instruments that usually slow down on-site activities.

In this flow of activities, VR technologies are introduced in the present paper for the representation and the management/sharing of data in a "virtual" method as an innovative tool by the methodological approach detailed in the next section.

\section{METHOD AND TOOLS}

The main goal of this paper is to develop a methodological process based on VR technologies and tools in order to support all the operators involved in the knowledge phase, for any kind of Cultural Heritage. In fact, the proposed methodology aims at the digitalization of knowledge, overcoming the traditional process of knowledge for the state of conservation and decay of a cultural site, as well as the process of cataloguing and sharing the collected data.

In detail, methodology takes advantage of VR techniques in realizing digital models of existing heritage and in elaborating dynamic thematic maps to support the analysis and the representation of material pathologies and decay, by spherical photos. However, it is necessary to introduce useful tools to achieve these goals.

Among all the available techniques for the creation of virtual environments, Virtual Tours are identified as a smart technique because of the use of panoramic images. Specifically, the use of spherical images allows a continuous representation and visualization of any digital sub-environment - as the elementary unit of the whole object to re-present in the virtual environment. Moreover, the fully fruition of environments is ensured by rotations of the scene (Cardaci, Versaci, 2013) both horizontally $\left( \pm 180^{\circ}\right)$ and vertically $( \pm 90)$.

The use of spherical photos is an inexpensive technique because of the low costs of required tools (spherical head, tripod and remote control for remote photo shooting) and smartness in creating spherical images themselves. In fact, those are the result of a processing phase (acquisition of wide-angle images, alignment of them and photo-stitching) usually performed by the camera (Cardaci et al., 2013). However, due to the nature of photographic shots, inherent characters and geometric features of each sub-environment require to be evaluated before the acquisition. The spherical scene - the result of the single-shot - is fully representative of a room featured by comparable geometric characters in the three dimensions. So, when sub-environments are featured by predominant geometric characters (for example the heights in the cloisters or the length in the corridors) several acquisitions are required to ensure a good overlapping.

The panoramic images can be visualized in two ways:

- as an equirectangular photo (distorted photo-plane) by traditional visualization tools;

- in a full-screen mode, well-calibrated to the camera lens and in an immersive way by common viewers, such as Quicktime or Flash and Java (Zonno et al., 2012).

Consequently, the photo-editing process, useful for mapping the virtual environment (RGB elements), can take place by the projection of raster information (solid lines and screens) both on the equirectangular picture - as a simple image - or directly on the spherical visualization. In the first case, any photo-editing software or image manager (Autocad $\AA$, Paint, Photoshop $®$, etc.) can be used to map equirectangular images, while few specific not open-source software - such as Photoshop CC® are required to map all the information in the spherical projection. However, the latter way helps technician in on-desk activities of mapping thanks to the wider and continuous fruition of the environment, solving potential discontinuities in mapping along the upper (ceiling) and lower parts (floor) of the scene (cracks and damp surfaces that involve vaults and adjacent walls are emblematic cases).

Finally, all the Virtual Tour software that use panoramic images allow the creation of digital environments as an ordered system (georeferenced) of spherical images linked together by specific relations. In detail, three classes of elementary unities compound the Virtual Tour:

- the scenes allow the fruition of the single virtual subenvironment;

- the media as the additional contents of scenes having various nature (.jpeg, .pdf, .tiff, .doc);

- hotspots define the relations between each entity according to which:

- each Virtual Tour is generated by $n$ scenes;

- each scene is connected to $n$ hotspots,

- each hotspot links a media.

Nowadays, the available Virtual Tour software creator are evolutions of the Krpano program, the first application conceived by the Austrian programmer K. Reinfield. It had not a graphical 
interface and it was implementable exclusively in .xml language. Among the commercial ones, Tourweaver@, 3D Vista Virtual Tour@, Panotour $\odot$, My 360®, Real Estate Virtual Tours Creator@ and VirtualTourEasy(C) are the most used for the described purpose (Cardaci, Versaci, 2013). The creation of a Virtual Tour by spherical images consists of three main phases:

1.importing the acquired images and processing them in the virtual tour creation software;

2.connecting the scenes by hotspots;

3.implementing information and documentary contents.

Downstream the description of the VR tools -deemed compliant with the goals-, the methodology follows, overlapping the described innovative tools of representation and virtual visualization to the traditional process of knowledge for cultural heritage. The proposed methodology is conceived following 4 phases (Figure 1):

\begin{tabular}{|c|c|c|c|}
\hline PHASE & AIM & DATA & EXTENSION \\
\hline$\frac{\Delta}{0}$ & \multirow{3}{*}{$\begin{array}{l}\text { Acquisition and digitization } \\
\text { of preliminary information }\end{array}$} & n Historical media & \multirow{3}{*}{$\begin{array}{l}. j p e g, \text {.pdf, } \\
\text {.tiff, .doc }\end{array}$} \\
\hline$\frac{0}{3}$ & & n Diagnostic media & \\
\hline$\frac{\vec{n}}{4}$ & & n Graphic survey & \\
\hline 胥 & $\begin{array}{l}\text { Acquisition of spherical } \\
\text { photos }\end{array}$ & n Sph_RGB & .jpeg \\
\hline $\begin{array}{l}\frac{0}{ \pm} \\
\frac{\pi}{0} \\
\frac{0}{0} \\
\frac{\pi}{4} \\
\text { m }\end{array}$ & $\begin{array}{l}\text { Mapping of the spherical } \\
\text { photos }\end{array}$ & n Sph_Map & .jpeg \\
\hline 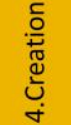 & $\begin{array}{l}\text { 4. Creation of the virtual } \\
\text { environment }\end{array}$ & $\begin{array}{l}\text { VT_RGB } \\
\text { VT_Map }\end{array}$ & .html \\
\hline
\end{tabular}

Figure 1. Methodology framework.

Ph1. Knowledge phase aimed at the acquisition of preliminary information (collection of historical data, graphic surveys, iconographic and photographic records); it represents the starting point for the knowledge of the artefact, as the first input to reach a correct survey (Perogalli, 1961). Compared to the described VR tools, the knowledge of morpho-constitutive characters of the heritage supports the planning activities of spherical photos acquisition (number and location), as well the recognition of the state of the site (low level of lighting, absence of horizontal surfaces for acquisitions, etc.). At the same time, the phase allows the recognition of the nature of collected data - the extension of media - that will be implemented in the virtual environment by specific relations (hotspots);

$\mathrm{Ph} 2$. Phase of survey aimed at heritage reading; in the digitization process, it coincides with the acquisition phase of spherical images (Sph_RGB) according to the planned framework of previous phase; whereas, all the measurement and interpretation activities not related to the mapping activities and/or derived from the reading of the collected documentation remain as in loco activities;

Ph3. On-desk mapping phase of the acquired spherical photos; it aims at the identification and representation of the state of decay (Sph_Map) by the projection of raster information through photo-editing software; this phase replaces the creation of survey sheets and their revision through the reading of collected information during the traditional photographic survey process;

$\mathrm{Ph} 4$. Creation of virtual environment of Cultural Heritage.
This phase constitutes the "virtualization" of the analysed site and the "Augmentation" of the virtualized environment with additional and specialized information (knowledge); these actions follow a double implementation process within the same Virtual Tour, according to the flowchart in Figure 2. The virtual environment is structured as a system of two parallel virtual tours featured by the same geometric and spatial properties of the scenes, but differing in contents of the scenes. The first virtual tour (VT_RGB) constitutes the visible geometric model and it is structured organizing the collected spheres in phase 2 ( $n$ Sph_RGB) according to the logical distribution of single areas in the site. The second one is configured as the conservative virtual tour (VT_Map) in which the scenes coincide with the spherical ones mapped in phase 3 ( $n$ Sph_Map). Both kinds of spherical images are introduced in the Tours guaranteeing the same orientation and connecting to each other $\left(n_{\mathrm{i}}\right.$ Sph_RGB $\leftrightarrow n_{\text {i Sph_Map) }}$ in order to ensure the transition from RGB to mapped visualization. This process allows to manage both the current state of the site (VT_RGB) and its enhancement by the experience of the technician, by the conservative level of knowledge (VT_Map) conceived

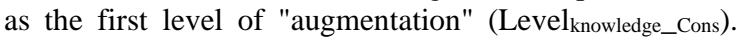
Simultaneously, the Virtual Tour of real environment

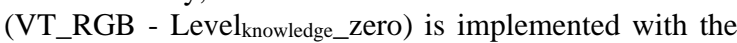
collected data in phase 1, linking media to single scenes by specific hotspots. These data will be displayed within the main scene as searchable and/or navigable elements according to its features (static images or file and 3D model, respectively). Here, the relation between scene and media cannot be bijective because multiple media can be linked to the same scene $\left(n_{\text {i Sph_RGB }} \leftrightarrow\left\{n_{\text {i media, }}, n_{\text {j media }}, n_{\mathrm{k}}\right.\right.$ media, ...\}). That degree of knowledge constitutes the historical-technical level of knowledge

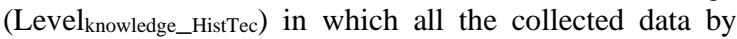
technicians are inserted, viewable and accessible.

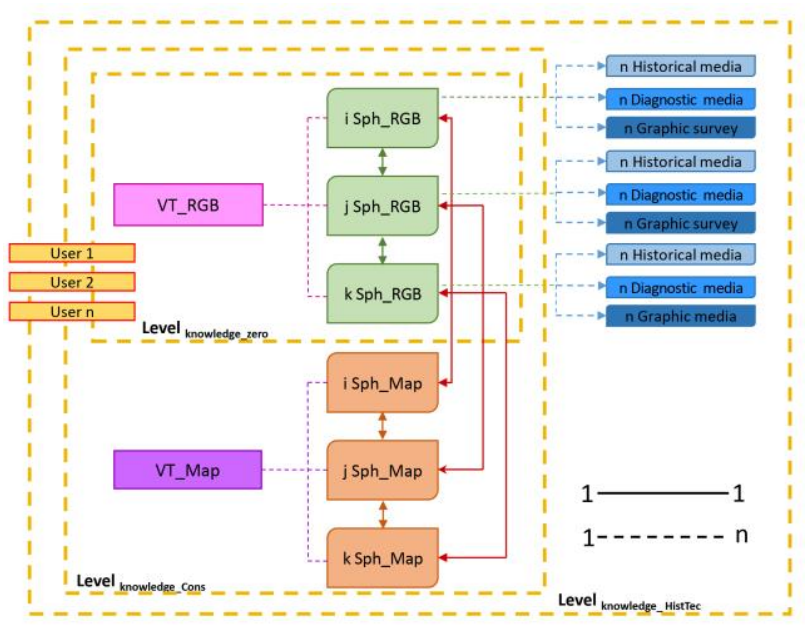

Figure 2. Logical - technical flowchart applied in the Phase 4.

So, the proposed methodology aims to conceive a virtual analysis of the state of conservation for architecture or sites, by VR tools, digitalizing and making available all collected and derived data (state of conservation and historic information) in any time and from any workplace, reducing the stay on site. That constitutes a benefit especially for places featured by compromised stability (e.g. post-disasters) or characterized by very poor environmental conditions for technicians (e.g. 
archaeological excavations, environments without ventilation and natural lighting). Furthermore, the creation of a digital model very faithful to real one and accessible at any time constitutes an additional advantage for the analysis and subsequent study of the artefacts, enriching the level of knowledge also in a temporal point of view.

\section{THE CASE STUDY OF THE CRYPTOPORTICUS IN THE ARCHAEOLOGICAL SITE OF EGNATIA}

\subsection{Introduction of the case study}

The archaeological site of Egnatia was located at the northern limit of the Messapian region. Today, it is in the city of Fasano, near to Brindisi, at the south of Apulia region (Italy). The Archaeological Park of Egnatia preserves large and significant monumental ruins of the Messapian and Roman city. Massive defensive walls (16000 $\mathrm{m}$ long) defined the urban space including an area of about 40 hectares.

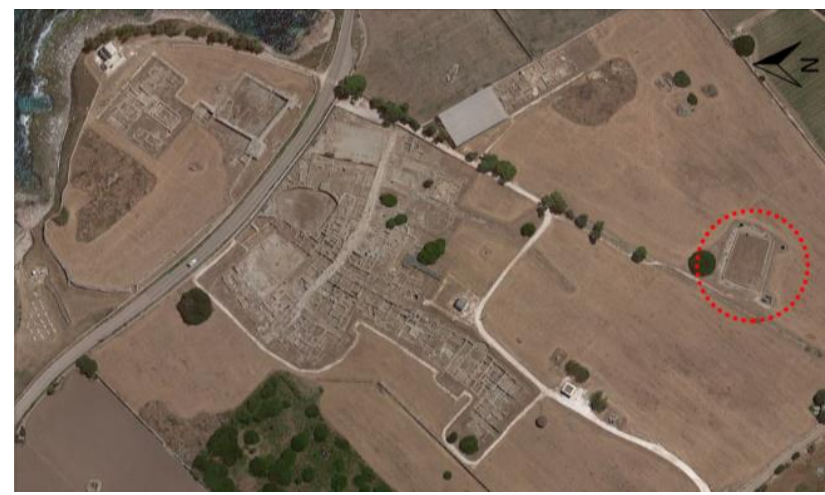

Figure 3. Aerial overview of the archaeological site of Egnatia and localization of the Cryptoporticus

The Cryptoporticus, built at the end of the first century B.C., is part of the archaeological site, located at the southern part (Figure 3 ). It is a four-wing underground structure, partly dug into the rock and covered with a barrel vault made of cement, stone and mortar using the opus incertum technique; however, the walls of vaulted galleries were made of regular square stone, or simply carved out of the rock. Finally, the entrances were built using the opus reticolatum technique or cubilia (Bianchi, 1993).

Moreover, two couples of entrances, altered over the time, show that the Cryptoporticus was used for different purposes, as a public warehouse for food products.

On the higher part of walls defining the inner perimeter of the Cryptoporticus, small openings - shaped as lunettes - allowed lighting and air circulation. Today, the vegetation obstructs these openings and the structure has a low level of lighting.

\subsection{Application of methodology for the creation of Virtual Tour of the Cryptoporticus}

Methodology and tools described in section 2 have been applied to the Cryptoporticus of the Archaeological Park of Egnatia. It was chosen as case study due to its representativeness as archaeological sites with low levels of accessibility and lighting as well as for its bad state of maintenance.

Applying the first knowledge phase of the methodology (Ph1), the historical research was carried out consulting mainly paper documents concerning:
1)Textual documentation (manuscripts, miscellany, historical items and ancient volumes);

2)Cartographies, drawings and maps related to different periods. The historical plans and drawings of the city of Egnatia were collected in that phase. Starting from them, the planning of photographic survey was defined following a system of adjacent spherical shootings in order to solve the extended geometry of corridors; in detail, 22 spherical images were identified along the plan, pointing out their position, steps and number; the planning aimed at guaranteeing the visual connection between spherical shots in order to cover all the surfaces and to ensure a good overlap between contiguous scans (Figure 4);

3)Historical photos, information about the state of maintenance of the Cryptoporticus in different moments. In particular, historical photographs derive from the archive of the National Archaeological Museum of Egnatia; specific points within the undergrounded structures were shot in 1965 and 1981-82. These sources were useful for the critical analysis of cracking and decay development along the surfaces (Figure 5);

4)Iconographies of historical representations of various kinds.

Following the knowledge phase, the photo acquisition was carried out in line with the $\mathrm{Ph} 2$ and according to the planned activities.

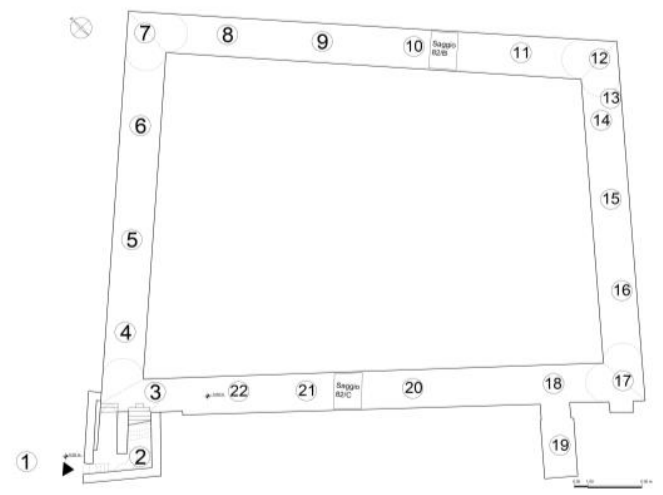

Figure 4. Plan of spherical acquisition

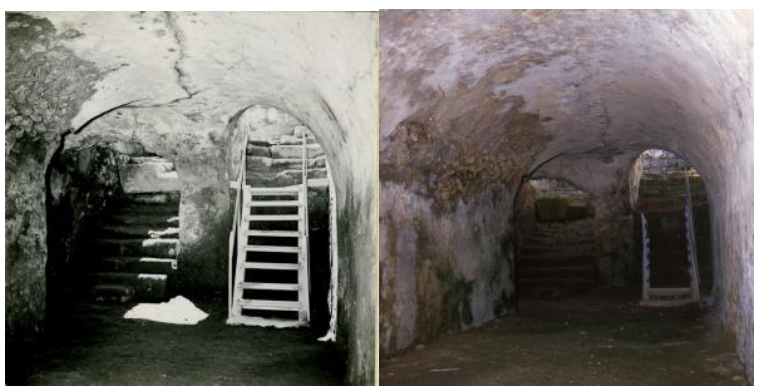

Figure 5. Historical images of an entrance of the Cryptoporticus in different years: On the left, 1965. On the right, 1981-82.

Spherical images were obtained using a combined system of devices defined by: a Samsung Gear 360 camera characterized by two $180^{\circ}$ lenses arranged on two sides (the spherical head camera), a tripod and a led rod in order to solve the low level of lighting (Figure 6). In detail, the camera has technical properties: Image sensor: CMOS, 15.0 MP x2; Default Output Pixel (Count Equivalent to): 25.9 MP; Lens: f / 2.2. Moreover, an additional photographic survey was carried out, using a Canon EOS 100D digital camera, with 18-55 mm lens. 


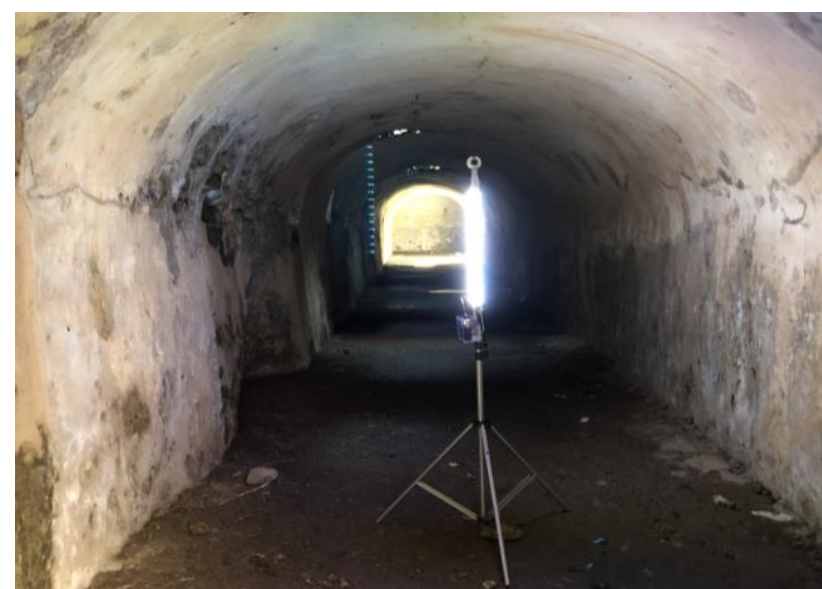

Figure 6. Composite system used for the acquisition of spherical images

After the acquisitions of the equirectangular images and the photographic survey, the on-desk mapping phase of the spherical images followed $(\mathrm{Ph} 3)$. The photo-editing process for the 22 collected equirectangular ( $n_{1-22}$ Sph_RGB) was carried out projecting raster information (lines and screens) to the RGB images displayed in a spherical environment (in detail Photoshop CC( $)$ 2019). The spherical visualization was fundamental in mapping activities because of the presence of cracks and decays along the vaults; moreover, four predominant typologies of surface decays were highlighted: detachment, biological colonization, washout and plant. For each spherical image, the state of conservation has been reported according to the UNI $11182 / 2006$. Surfaces affected by decays were mapped with semi-solid coloured filling, while cracks were retraced with lines. Colours of fillings were chosen aiming at their readability inside the virtual environment, so avoiding the overlapping with the real colour of surfaces. At the end of the process, the 22 mapped images were organized following the same sequence as those acquired on-site ( $n_{\mathrm{i}}$ Sph_Map $\leftrightarrow n_{\mathrm{i}}$ Sph_RGB) (Figures 7 and 8).

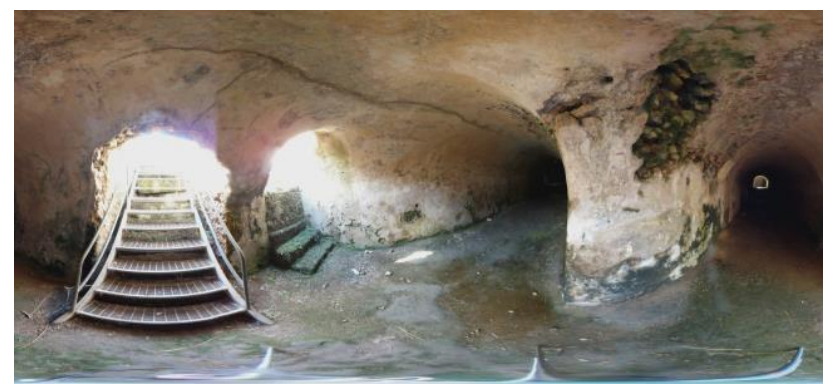

Figure 7. Equirectangular image the Cryptoporticus (n3 Sph_RGB)

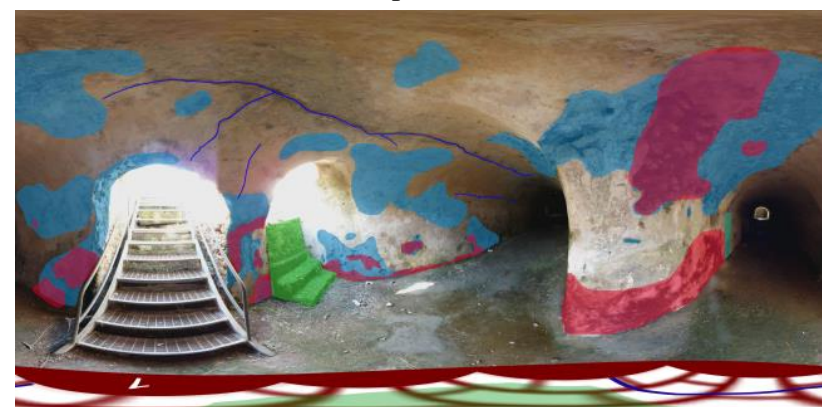

Figure 8. Equirectangular mapped image of the Cryptoporticus (n3 Sph_Map) in the photo-plane visualization
The virtual environment of the Cryptoporticus was created $(\mathrm{Ph} 4)$ using Tourweaver $\odot$ software. Digital environment was structured following the logical process described in section 2, so assigning a double parallel path to the structure of virtual environment (VT_RGB and VT_Map). To support the reading, an interactive map has been inserted helping users in choosing the virtual environment to display (Figures 9 and 10).

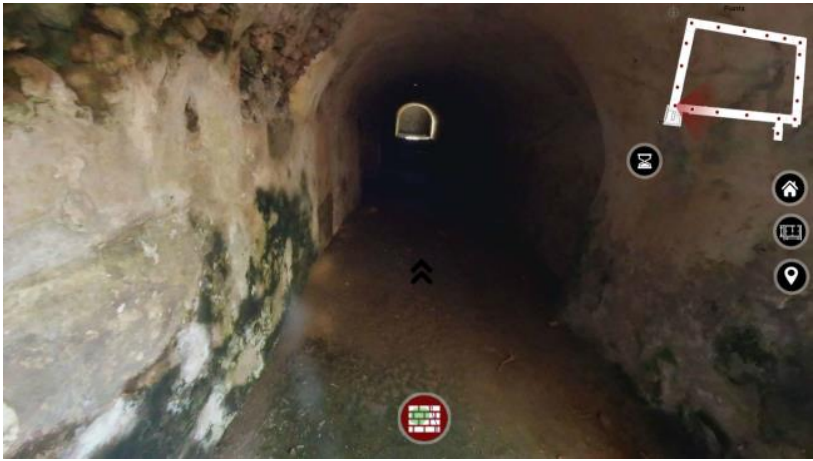

Figure 9. Spherical visualization of the $\mathrm{n} 3$ equirectangular image in the VT_RGB

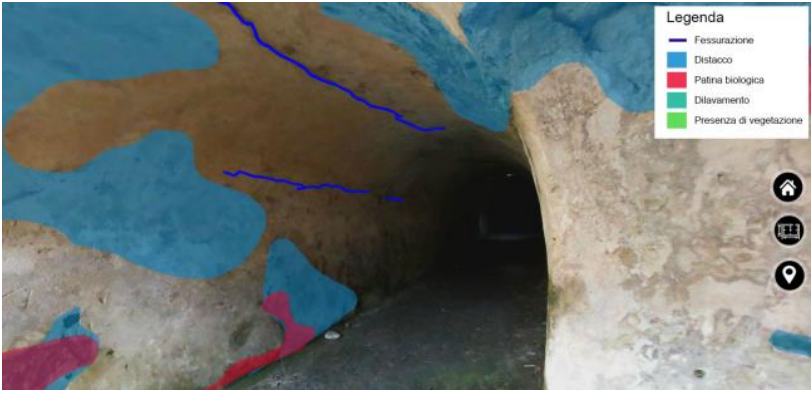

Figure 10. Spherical visualization of the $n 3$ mapped equirectangular image in the VT_Map (Level knowledge_Cons)

Finally, a legend for decays (with specific hotspot) was introduced in all the mapped scenes, in order to support the reading and completing the first level of augmented knowledge (Levelknowledge_Cons).

The data collected in the first phase were digitized (mainly paper) and, after their classification, were included in the VT_RGB, enriching the basic database. These data were catalogued for their information nature and position. Specifically for the case of the Cryptoporticus of Egnatia, two macro-classes of hotspots were created guaranteeing the univocal reading of relations between scene and related media:

Historical datasheets make available to users all the information derived from historical research, combining textual documentation and graphic information (Figure 11);

Diagnostic datasheets show the temporal evolution of the decay. This case derives from the opportunity to evaluate in a qualitative way the process of variation of decay along one of the two entrances. The chrono-historical information of the process was obtained implementing the photographic data with an adding shooting series located in the same position as the historical ones; a specific sheet representing the variation of decay framework over time was added to the referred scene (Figure 12). Here, the application to the mapping process on a traditional photographic basis highlighted how the entire process - also on spherical images - can potentially be implemented over time, also with results of diagnostic tests. 
Near to the others, specific hotspots were introduced allowing the movement in the scenes (e.g. to pass from a scene to another) and linking the mapped tour with the conservative data. The latter ones allowed all users to choose the themes to display (Level $l_{\text {knowledge_HistTec or Level }}$ knowledge_Cons) and to have bibliographic information useful for further surveys. Thereby, the virtual tour allowed the direct reading of the structure, from the construction elements to the material features, as well as its state of decay.

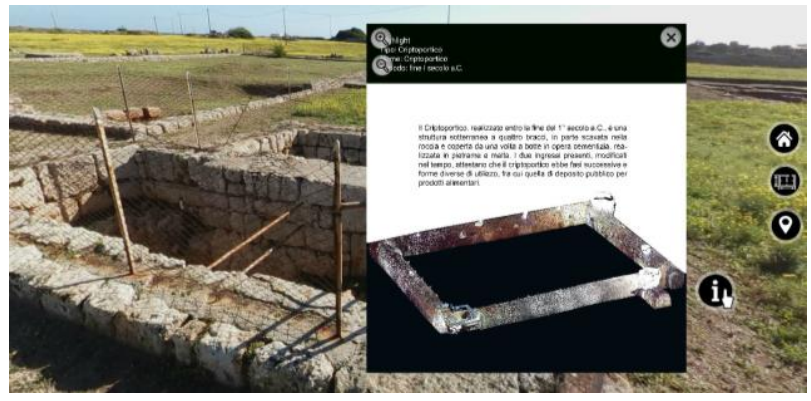

Figure 11. Visualisation of an historical datasheets in the VT_RGB

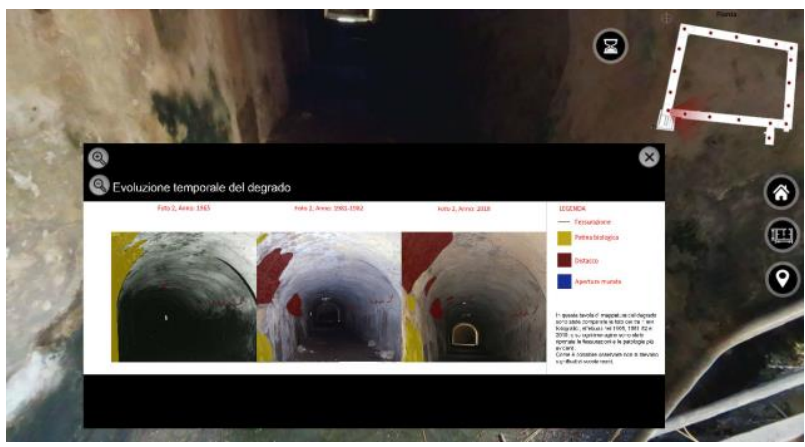

Figure 12. Visualisation of a diagnostic datasheets in the VT_RGB

\section{CONCLUSION}

In addition to its promotion through Virtual and Augmented Reality, the Cultural Heritage sector represents the main beneficiary of VR tools still in technological growth. The touristcultural fruition, the reconstruction of environments or parts of them, as well as the creation of virtual environments as databases of the cultural information in a digitalized version represent the applications already validated in the Architecture and Cultural Heritage fields. However, the management of heritage in a technical point of view still represents an opportunity to exploit these technologies. In that context, the presented paper frames the available tools, investigates their potential development and proposes a methodology that should support the phase of knowledge for Cultural Heritage. In depth, the methodology includes VR tools applying them for the analysis of the state of site and conservation. Moreover, the tools connected to the digitalisation processes are calibrated for the technical fruition of building and they become fundamental in transferring information between the various figures involved in the process (from the technicians in collecting historical data, in filling the survey sheets to the preservation authorities in checking the choices). Focus on the IT point of view, these figures represent different users involved in the fruition and the interaction of digitally organized contents. Moreover, the work analyses technologies in the field of photography, focusing on spherical images; for them, all the advantages, such as the speed of acquisition, the representativeness and continuity in the full-screen visualization and the speed in creating the structured database (Virtual Tour) were analysed. The application of the structured methodological flow allows to verify its effectiveness and potential use for the sites characterized by operative critical conditions; it is the case of an archaeological undergrounded site devoid of light and ventilation, because of its state of maintenance. At the same time, the methodology could find high potentialities in post-disaster emergencies where safety conditions discriminate the choices in planning the investigation process.

The "virtualization" process of the case study highlighted the potential of tools also in a temporal analysis. The opportunity offered by the presence of archival information about the state of maintenance - in a specific historical moment of the site supported the potential implementation of them in the actual state; moreover, it expresses the potential opportunity to derive qualitative information on the undergone processes, obtaining immediately readable graphic results. Despite the higher potentialities, certainly future developments require to be introduced and discussed. First of all, the impossibility to replace the mapping process with an on-site activity; the projection of decays information, as in the methodological flow, is still linked to the on-desk activities; even if it is functional for critical cases, it represents a physical obstacles in ending faster the onsite activities for traditional cases. However, authors want to highlight that among the projects supporting these results, the VERBUM project is trying to overcome that operative constraint; the project is implementing specific mapping tools directly inserted in spherical environment and within the platform itself, thus including tools currently available in not open source photo-editing software (e.g. Photoshop( $)$ ). Also, the necessity to export all the information mapped in a spherical environment on a geometric model (CAD models) according to a semi-automatic process. That feature also characterizes the current process of investigation and creation of sheets for the state of the sites by technicians, especially aiming at the implementation of data in geometric and parametric systems such as BIM and HBIM to which all the Cultural sites (as public) are directly subject according to the legislation.

\section{ACKNOWLEDGEMENTS}

The authors would like to acknowledge the Apulia Region for funding and supporting the VERBUM Project (call for Innonetwork activities - Sostegno alle attività di R\&S per lo sviluppo di nuove tecnologie sostenibili, di nuovi prodotti e servizi - POR Puglia FESR-FSE 2014-2020 - Asse I - Azione 1.6) for the scientific and computer-based evaluation of instruments and protocols declined to the technical knowledge of the cultural heritage. Moreover, they acknowledge the authority of INTERREG IPA CBC (co-funded by the European Union through the Instrument for Pre-Accession (IPA II)) for funding and supporting the 3D-IMP-ACT project in supporting these innovative activities in the archaeological sites involved in the project. Finally, authors thank the Polo Museale in providing and sharing with them historical data of Cryptoporticus that will be published into the paper.

\section{REFERENCES}

Aznoora, O., Wahab, N. A., Mohammad, H. I., 2009. Development and Evaluation of an Interactive 360 Virtual Tour for Tourist Destinations. Journal of Information Technology Impact, 9(3), 173-182.

Ben-Joseph, E., Ishii, H., Underkoffler, J., Piper, B., Yeung, L., 2001. Urban simulation and the luminous planning table: Bridging the gap between the digital and the tangible. Journal of Planning Education and Research, 21(2), 196-203. 
Bianchi, V., 1993. Citazioni e visitazioni del Criptoportico di Egnazia. "Fasano" - Rivista Di Cultura, 5-23.

Bruno, F., Bruno, S., De Sensi, G., Luchi, M.-L., Mancuso, S., Muzzupappa, M., 2010. From 3D reconstruction to virtual reality: A complete methodology for digital archaeological exhibition. Journal of Cultural Heritage, 11(1), 42-49.

Carbonara, G., 2012. Disegno e documentazione per il restauro: un impegno interdisciplinare. Disegnarecon, 5(10), 21-26.

Cardaci, A., Versaci, A., 2013. L'innovazione nel rilievo fotografico per la conoscenza, la documentazione e la fruizione dei beni culturali. DISEGNARECON, 6(12), 1-10.

Cardaci, A., Versaci, A., Fauzia, L. R., 2013. Nuove tecniche fotografiche per la documentazione, la valorizzazione e la divulgazione del patrimonio culturale: high dynamic range imaging, photo stitching e virtual tour. IX Conferenza Del Colore, 270-281.

Cobb, S., Neale, H., Crosier, J., Wilson, J. R., 2002. Development and evaluation of virtual environments for education. In Handbook of virtual environments (pp. 951-976). CRC Press.

D’Auria, S., 2018. Fotomodellazione con immagini da smartphone per la diffusione della conoscenza dei Beni Culturali. GEOmedia, 22(1).

De Fino, M., Galantucci, R. A., Fatiguso, F., 2019a. Mapping and monitoring building decay patterns by photomodelling based 3D models. Tema: Technology, Engineering, Materials and Architecture, 5(1), 27-35.

De Fino, M., Galantucci, R. A., Fatiguso, F., 2019b. Remote diagnosis and control of the heritage Architecture by photorealistic digital environments and models. SCIRES-ITSCIentific RESearch and Information Technology, 9(2), 1-16.

De Paolis, L. T., 2012. Applicazione interattiva di realtà aumentata per i beni culturali. SCIRES-IT-SCIentific RESearch and Information Technology, 2(1), 121-132.

De Souza e Silva, A., Delacruz, G. C., 2006. Hybrid reality games reframed: Potential uses in educational contexts. Games and Culture, 1(3), 231-251.

Docci, M., Maestri, D., 1994. Manuale di rilevamento architettonico e urbano. Laterza Roma.

Frate, M. C., 2010. Restauro e conservazione del patrimonio storico. D. Flaccovio.

Fuchs, H., Livingston, M. A., Raskar, R., Keller, K., Crawford, J. R., Rademacher, P., Drake, S. H., Meyer, A. A., 1998. Augmented reality visualization for laparoscopic surgery. International Conference on Medical Image Computing and Computer-Assisted Intervention, 934-943.

Gabellone, F., 2014. Approcci metodologici per una fruizione virtuale e arricchita dei Beni Culturali. Arkos (Torino - Milano), 2.

Gillet, A., Sanner, M., Stoffler, D., Goodsell, D., Olson, A., 2004. Augmented reality with tangible auto-fabricated models for molecular biology applications. IEEE Visualization 2004, 235-241.

Guttentag, D. A., 2010. Virtual reality: Applications and implications for tourism. Tourism Management, 31(5), 637-651.
Julier, S., King, R., Colbert, B., Durbin, J., Rosenblum, L., 1999. The software architecture of a real-time battlefield visualization virtual environment. Proceedings IEEE Virtual Reality (Cat. No. 99CB36316), 29-36.

Kaufmann, H., Schmalstieg, D., 2002. Mathematics and geometry education with collaborative augmented reality. ACM SIGGRAPH 2002 Conference Abstracts and Applications, 37-41.

Limoncelli, M., 2011. Applicazioni digitali per l'archeologia: il restauro Virtuale. DigItalia, 1, 42-59.

Marino, L., 1990. Il rilievo per il restauro: ricognizioni, misurazioni, accertamenti, restituzioni, elaborazioni.

Meschini, A., 2011. Tecnologie digitali e comunicazione dei beni culturali. Stato dell'arte e prospettive di sviluppo. Disegnarecon, 4(8), 14-24.

Milgram, P., Kishino, F., 1994. A taxonomy of mixed reality visual displays. IEICE TRANSACTIONS on Information and Systems, 77(12), 1321-1329.

Paolini, P., Di Blas, N., Alonzo, F., 2005. ICT per i Beni Culturali esempi di applicazione. Mondo Digitale, 3, 44.

Perogalli, C., 1961. Casistica e metodologica del restauro architettonico. In Il restauro architettonico (pp. 29-64).

Pietrzak, P., Arya, M., Joseph, J. V, Patel, H. R. H., 2006. ThreeDimensional Visualization in laparoscopic surgery. $B J U$ International, 98(2), 253-256.

Rashid, O., Bamford, W., Coulton, P., Edwards, R., Scheible, J., 2006. PAC-LAN: mixed-reality gaming with RFID-enabled mobile phones. Computers in Entertainment (CIE), 4(4), 4-es.

Roders, M., Piaia, E., Sebastian, R., 2016. INSITER selfinspection method and instruments to ensure optimal performance of prefab retrofitting solutions. SBE16 CONFERENCE, 33-42.

Romero, L., Santiago, J., Correia, N., 2004. Contextual information access and storytelling in mixed reality using hypermedia. Computers in Entertainment (CIE), 2(3), 12.

Roussou, M., 2004. Learning by doing and learning through play: an exploration of interactivity in virtual environments for children. Computers in Entertainment (CIE), 2(1), 10.

Russo, M., Manferdini, A. M., 2015. Dal rilievo alle rappresentazioni ad alta risoluzione dello spazio architettonico continuo. Il caso di studio del complesso dell 'Abbazia di Pomposa.

Vlahakis, V., Karigiannis, J., Tsotros, M., Gounaris, M., Almeida, L., Stricker, D., Gleue, T., Christou, I. T., Carlucci, R., Ioannidis, N. (2001). Archeoguide: first results of an augmented reality, mobile computing system in cultural heritage sites. Virtual Reality, Archeology, and Cultural Heritage, 9(10.1145), 584993-585015.

Zoellner, M., Stricker, D., Bleser, G., Pastarmov, Y. (2007). iTACITUS-novel interaction and tracking paradigms for mobile AR. The European Research Network of Excellence in Open Cultural Heritage (EPOCH), 110-117.

Zonno, M., Capotorto, S., Maiellaro, N. (2012). Fotografia immersiva applicata ai beni culturali. 